Published in final edited form as:

Eur Urol. 2016 May ; 69(5): 894-903. doi:10.1016/j.eururo.2015.12.005.

\title{
Testosterone Therapy in Men With Prostate Cancer
}

\author{
Alan L. Kaplan a, ${ }^{\star}$, Jim C. Hub ${ }^{b}$ Abraham Morgentaler ${ }^{c}$, John P. Mulhalld, Claude C. \\ Schulmane, and Francesco Montorsi ${ }^{\dagger}$ \\ Alan L. Kaplan: alkaplan@mednet.ucla.edu \\ aDepartment of Urology, David Geffen School of Medicine at UCLA, Los Angeles, CA, USA

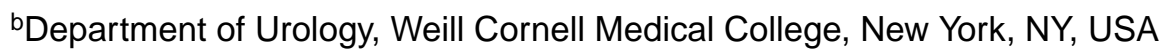 \\ cMen's Health Boston, Harvard Medical School, Boston, MA, USA \\ dSexual and Reproductive Medicine Program, Urology Service, Memorial Sloan Kettering Cancer \\ Center, New York, NY, USA \\ eDepartment of Urology, Erasme Hospital, Brussels, Belgium \\ fDepartment of Urology, Universita Vita-Salute San Raffaele, Milan, Italy
}

\begin{abstract}
Context-The use of testosterone therapy in men with prostate cancer was previously contraindicated, although recent data challenge this axiom. Over the past 2 decades, there has been a dramatic paradigm shift in beliefs, attitude, and treatment of testosterone deficiency in men with prostate cancer.
\end{abstract}

Objective-To summarize and analyze current literature regarding the effect of testosterone replacement in men with prostate cancer.

\footnotetext{
*Corresponding author. The University of California, Los Angeles, Department of Urology, 10833 Le Conte Avenue, PO Box 951738, Los Angeles, CA 90095, USA. Tel. +44-001-202-531-4103.

Author contributions: Alan L. Kaplan had full access to all the data in the study and takes responsibility for the integrity of the data and the accuracy of the data analysis.

Study concept and design: Kaplan, Schulman, Morgentaler, Hu, Mulhall, Montorsi.

Acquisition of data: Kaplan, Schulman, Morgentaler.

Analysis and interpretation of data: Kaplan, Schulman, Morgentaler, Hu, Mulhall, Montorsi.

Drafting of the manuscript: Kaplan.

Critical revision of the manuscript for important intellectual content: Kaplan.

Statistical analysis: Kaplan, Schulman, Morgentaler.

Obtaining funding. None.

Administrative, technical, or material support: Kaplan.

Supervision: Schulman, Morgentaler, Montorsi.

Other: None.

Financial disclosures: Alan L. Kaplan certifies that all conflicts of interest, including specific financial interests and relationships and affiliations relevant to the subject matter or materials discussed in the manuscript (eg, employment/affiliation, grants or funding, consultancies, honoraria, stock ownership or options, expert testimony, royalties, or patents filed, received, or pending), are the following: Morgantaler: consulting or advisory boards (AbbVie, Clarus, Endo, TesoRx), research grants (Antares, Endo, Eli Lilly), and lecture honoraria (Bayer, Pfizer, Lipocine).

Publisher's Disclaimer: This is a PDF file of an unedited manuscript that has been accepted for publication. As a service to our customers we are providing this early version of the manuscript. The manuscript will undergo copyediting, typesetting, and review of the resulting proof before it is published in its final citable form. Please note that during the production process errors may be discovered which could affect the content, and all legal disclaimers that apply to the journal pertain.
} 
Evidence acquisition-We conducted a Medline search to identify all publications related to testosterone therapy in both treated and untreated prostate cancer.

Evidence synthesis-The historical notion that increasing testosterone was responsible for prostate cancer growth was based on elegant yet limited studies from the 1940s and anecdotal case reports. Current evidence reveals that high endogenous androgen levels do not increase the risk of a prostate cancer diagnosis. Similarly, testosterone therapy in men with testosterone deficiency does not appear to increase prostate cancer risk or the likelihood of a more aggressive disease at prostate cancer diagnosis. Androgen receptor saturation (the saturation model) appears to account for this phenomenon. Men who received testosterone therapy after treatment for localized prostate cancer do not appear to suffer higher rates of recurrence or worse outcomes; although studies to date are limited. Early reports of men on active surveillance/watchful waiting treated with testosterone have not identified adverse progression events.

Conclusions-An improved understanding of the negative effects of testosterone deficiency on health and health-related quality of life - and the ability of testosterone therapy to mitigate these effects-has triggered a re-evaluation of the role testosterone plays in prostate cancer. An important paradigm shift has occurred within the field, in which testosterone therapy may now be regarded as a viable option for selected men with prostate cancer suffering from testosterone deficiency.

Patient summary-In this article, we review and summarize the existing literature surrounding the use of testosterone therapy in men with prostate cancer. Historically, testosterone was contraindicated in men with a history of prostate cancer. We show that this contraindication is unfounded and, with careful monitoring, its use is safe in that regard.

\section{Keywords}

Testosterone; Androgens; Testosterone therapy; Prostate cancer; Testosterone deficiency; Saturation mode

\section{Introduction}

Testosterone deficiency (TD; also known as hypogonadism) and prostate cancer are both highly prevalent in older men and may impair overall health and quality of life. Up to 25\% of elderly men experience TD [1-3] while the lifetime prevalence of a prostate cancer diagnosis in developed countries approximates 14\% [4]. Testosterone therapy is an effective, commonly used treatment for clinically significant testosterone deficiency. Testosterone therapy has been shown to be effective in mitigating the bothersome symptoms and metabolic sequelae of testosterone deficiency [5,6]. Despite strong evidence of benefit, a significant proportion of men with TD (those with concurrent or historical prostate cancer) are frequently denied treatment with exogenous testosterone. Until recently, it was considered axiomatic that testosterone therapy was contraindicated in men with prostate cancer. This was based on a strong historical tradition and circumstantial evidence that went unchallenged. The preponderance of data demonstrating the health and quality of life benefits of testosterone therapy has elicited a re-evaluation of classic assumptions regarding the effect of exogenous androgens on the prostate, especially in men with prostate cancer $[7,8]$. 
These assumptions date back to the 1940s and can be traced to the work of Charles Huggins. One of only two urologists that have been awarded a Nobel Prize, Huggins and Hodges' work described the role of androgens in prostate cancer progression [9]. Their research in men with metastatic prostate cancer established the androgen hypothesis- that prostate cancer development and growth is directly related to the degree of androgenic activity in the body. Their conclusion that cancer of the prostate is "activated" by androgens gave rise to the belief that raising serum androgens via the administration of exogenous testosterone to men with prostate cancer would necessarily promote malignant cell growth and disease progression [9].

Mounting evidence refuting the androgen hypothesis has emerged over the past decade and there are now numerous published case series indicating lack of apparent cancer progression among men with prostate cancer treated with testosterone therapy $[8,10]$. Nonetheless, there still remains a major concern among physicians that testosterone therapy may unmask occult prostate cancer in otherwise healthy men with TD, or may cause cancer recurrence or rapid progression in men with known prostate cancer, even after treatment and apparent cure [11]. The objective of this review is to explore these concerns in light of the existing data regarding testosterone and prostate cancer.

\section{Evidence acquisition}

We conducted a Medline search from 1940 to 2015 to identify all publications related to the use of testosterone in men with prostate cancer, treated or otherwise. We included original studies as well as review articles. Key words used in this search were "prostate cancer", "testosterone", "testosterone replacement", "testosterone therapy", "androgens", "hypogonadism", and "prostate specific antigen."

\section{Evidence synthesis}

\subsection{Historical perspective}

In a 1935 study, Kutscher and Wolbergs [12] found that acid phosphatase was present in higher concentrations in human and monkey prostate tissue than any other tissue in the body. This investigative advance allowed Huggins and Hodges [9] to study the effects of hormone manipulation in prostate cancer. It was known at the time that surgical castration would cause regression and clinical improvement of benign prostatic enlargement $[13,14]$. Huggins and Hodges [9] demonstrated that serum acid phosphatase activity decreased significantly in men with metastatic prostate cancer treated with orchiectomy or with estrogen treatment that was known to reduce testosterone secretion. Additionally, they found that injection of androgen (testosterone propionate) caused an increase of acid phosphatase above preinjection levels, which returned to baseline following cessation of the drug [9]. Huggins and Hodges [9] concluded that: (1) prostate cancer was influenced by androgenic activity in the body, (2) that disseminated prostate cancer is inhibited by androgen elimination, and that (3) prostate cancer is activated by androgen injections [10].

Largely based on these studies, surgical castration (bilateral orchiectomy) became the mainstay of treatment for men with metastatic prostate cancer for decades. Medical 
castration through androgen deprivation therapy (ADT) has largely supplanted bilateral orchiectomy; although the efficacy of both modalities is undisputed. Prostate specific antigen (PSA) has replaced serum acid phosphatase as the laboratory test of choice in prostate cancer for improved sensitivity and specificity. Men undergoing surgical or medical castration experience dramatic decrease in PSA and, in most cases, clinical disease regression. The positive experiences with ADT, Huggins' Nobel-prize winning work, and some anecdotal case reports, combined to create an axiomatic belief that exogenous androgen is contraindicated in men with prostate cancer. That belief has been largely unchallenged for 7 decades.

\subsection{TD}

Administration of exogenous androgen had, until recently, relatively few indications. Our emerging understanding of TD, its negative consequences, and the known benefits of testosterone therapy has led to a scientific re-evaluation of the risks of testosterone therapy, including its safety with regard to prostate cancer. Testosterone deficiency is a clinical syndrome consisting of a variety of characteristic symptoms and signs in combination with low serum testosterone concentrations. Symptoms include low libido, erectile dysfunction, reduced morning erections, depressed mood, and fatigue [15,16]. Signs include anemia, reduced muscle mass, increased fat mass, and reduced bone mineral density. Although prevalence estimates differ, the clinical entity of TD is common in adult men, and increases with aging (Table 1).

Repletion of androgen levels via testosterone therapy has been shown to ameliorate many of the negative consequences of TD, namely, body composition, metabolic control, psychological, and sexual parameters [17]. Meta-analyses of randomized trials demonstrate a reduction in fat mass and an increase in lean body mass and muscle strength in middleaged and older men on testosterone therapy $[18,19]$ (Level 1a, Grade A). Bone density in hypogonadal men of all ages in increased with testosterone [20] (Level 1b, Grade A). In men with sexual dysfunction, testosterone therapy yielded improvement in some aspects of libido and sexual performance [21] (Level 2a, Grade A). A meta-analysis demonstrated a positive effect on mood [22] (Level 1a, Grade A). The historical androgen hypothesis, as previously described, assumes a linear relationship between prostatic cancer cell growth and serum androgens- namely, that ever-higher serum androgen concentrations lead to ever-greater prostate cancer growth. This assumption has not been supported in literature. Firstly, there is no known correlation between serum testosterone levels and prostate size or PSA level [23]. Secondly, testosterone administration at supraphysiologic doses to volunteers without prostatic disease for periods up to 9 mo did not result in increased prostate volume or serum PSA [24]. Thirdly, large prospective studies have not shown a link between endogenous serum testosterone levels and risk of developing prostate cancer [8,23-25].

\subsection{Saturation model}

These data led to the development of the saturation model first proposed by Morgentaler in 2006 [7], and further refined by Morgentaler and Traish in 2009 [10]. This model resolves two distinct and seemingly contradictory observations. One is that both benign and malignant prostate tissues appear indifferent to variation in serum androgen concentrations 
throughout the normal concentration range, and the second is that there is clearly exquisite sensitivity to variation in androgen concentration at very low concentrations. The saturation model resolves this paradox by positing that there is a finite ability of androgens to stimulate prostate cancer growth.

Multiple mechanisms may contribute to this. The androgen receptor becomes saturated in human prostate tissue at approximately $4 \mathrm{nmol} / \mathrm{l}$ (approximately $120 \mathrm{ng} / \mathrm{dl}$ ) in vitro, corresponding to approximately $8 \mathrm{nmol} / \mathrm{l}(240 \mathrm{ng} / \mathrm{dl})$ in vivo due to the presence of binding hormones [26,27]. Marks et al [28] showed that androgen concentrations in prostatic tissue remained unchanged while patients were being treated with testosterone therapy despite large increases in serum testosterone. In the 2006 randomized, double blind, placebocontrolled trial, testosterone therapy showed no effect on prostate tissue histology, tissue biomarkers, gene expression, cancer incidence, or severity [28]. Likewise, in androgen sensitive prostate cancer cell lines, cell growth accelerated rapidly with androgen exposure but demonstrated a stabilizing dose response curve with increasing doses of androgen [7,9].

Empirically, the saturation point at which there is no further appreciable growth with increasing serum $\mathrm{T}$ concentration appears to be at approximately $240-250 \mathrm{ng} / \mathrm{dl}$, consistent with predicted values based on maximal androgen receptor binding to androgen. In the TRiUS registry, men with baseline serum $\mathrm{T}$ concentrations greater than $250 \mathrm{ng} / \mathrm{dl}$ did not demonstrate a rise in PSA [29]. Similarly, in a 6-mo prospective, placebo-controlled testosterone gel study, an increase in PSA was seen in men with baseline $\mathrm{T}<250 \mathrm{ng} / \mathrm{dl}$, but not in men with baseline T > $250 \mathrm{ng} / \mathrm{dl}$ [30]. Finally, Rastrelli et al [31] showed a naturally occurring saturation curve (Fig. 1) for PSA in 2967 men with a nearly identical saturation point of $8 \mathrm{nmol} / \mathrm{l}$ (approximately $240 \mathrm{ng} / \mathrm{dl}$ ).

\subsection{Does testosterone affect prostate cancer risk or severity?}

In a 2008 pooled-analysis study of 18 population-based longitudinal studies comprising 3886 men with prostate cancer and 6438 matched controls, Roddam et al [32] found no link between endogenous androgen levels and risk of developing prostate cancer. In a summary of the placebo arm of the Reduction by Dutasteride of Prostate Cancer Events trial, Muller et al [33] show that in 3255 men undergoing prostate biopsy at $2 \mathrm{yr}$ and $4 \mathrm{yr}$, prostate cancer risk was unrelated to serum androgen levels. As such, men with higher endogenous testosterone levels are not more likely to develop prostate cancer.

Although no randomized controlled trial has tested whether testosterone therapy increases the risk of developing prostate cancer, a 2005 meta-analysis of 19 randomized controlled trials by Calof et al [34] showed no statistically significant difference in prostate cancer diagnoses among those that used testosterone compared to placebo. Fenely and Carruthers [35] followed British men on testosterone therapy over time and found the risk of prostate cancer diagnosis to be similar to age-matched controls in the population. Shabsigh et al [36] confirmed these findings in a 2009 systematic review of 11 testosterone trials that did not show increase in prostate cancer risk in men that used testosterone therapy. Haider et al [37] reported a pooled cohort of 1023 patients on testosterone across three registries that were followed for a median of 5-yr duration. The prostate cancer incidence was lower than population levels estimated from American and European screening trials. In two 
population-based studies, both Kaplan and $\mathrm{Hu}$ [38] and Baillargeon et al [39] showed that prior use of testosterone therapy did not predispose to worse prostate cancer severity. Combined, these data can reliably quell concern that neither high endogenous testosterone nor exogenous androgen supplementation increase the risk of prostate cancer diagnosis [40]. Conversely, the risk of prostate cancer diagnosis - and/or worse prostate cancer severityhas been shown to be higher in men with low endogenous androgen levels [41,42]. Léon et al [43] found that low free and bioavailable testosterone levels were associated with highgrade prostate cancer at radical prostatectomy [43], although the consistency and clinical significance of these findings remain to be seen.

\subsection{Testosterone therapy in men treated for prostate cancer}

Throughout the early 2000s, clinical evidence discounting testosterone as a linear mechanistic cause of prostate cancer growth mounted. Additionally, alternative mechanistic hypotheses were offered (ie, the saturation model) as described above. This environment coupled with a growing understanding of the negative health effects and decreased quality of life in men with TD to induce a paradigm shift away from testosterone as a prostate cancer inducer. This shift provided clinicians with a new potential approach in the treatment of men with bothersome and symptomatic TD that had been previously treated for prostate cancer [10]. Published case series beginning in the mid-2000s reported on prostate cancer-specific safety of testosterone therapy.

The first published case series by Kaufman and Graydon [44] in 2004 reported no biochemical recurrences in seven men with predominantly low risk prostate cancer treated with radical prostatectomy. All PSAs were undetectable after surgery and remained so after testosterone administration. The median follow-up was 24 mo, although one patient was followed for 12 yr. Similarly, in 2005, Agarwal and Oefelein [45] reported undetectable PSA in 10 men with mostly intermediate risk prostate cancer treated with radical prostatectomy and subsequent testosterone. Median follow-up time was 19 mo. In 2009, Khera et al [46] reported their series of 57 men with predominantly low and intermediate risk disease treated with testosterone therapy for an average of 36 mo after radical prostatectomy. After a median follow-up time of 13 mo, there were no biochemical recurrences noted.

In a 2013 study, Pastuszak et al [47] reported their series of 103 hypogonadal men previously treated with radical prostatectomy that underwent testosterone treatment. Twenty six $(25 \%)$ men in the study had high-risk disease. The cohort was compared with 49 controls who did not receive testosterone. A statistically significant increase in PSA was noted in the treatment group during the median 27.5-mo follow up period while no increase was detected in the no-treatment group. Despite this PSA increase, however, there were actually more true prostate cancer recurrences in the control group [47].

In a 2007 study published in Cancer, Sarosdy [48] reported no biochemical recurrences in 31 men with mostly low-risk prostate cancer treated with brachytherapy. The median follow-up time was $5 \mathrm{yr}$ and neither Phoenix nor American Society for Radiation Oncology recurrence criteria were met in any patients. In a more recent brachytherapy study by Balbontin et al [49], none of the 20 men with predominantly low risk prostate cancer treated with brachytherapy experienced biochemical recurrence. The median follow-up time of this 2014 
study was $2.5 \mathrm{yr}$. In fact, PSA levels in this study actually decreased from $0.07 \mathrm{ng} / \mathrm{ml}$ to 0.01 $\mathrm{ng} / \mathrm{ml}$. In 2009, Morales et al [50] reported their series of five men that had undergone external beam radiation therapy (EBRT) and were subsequently treated with testosterone after they reached their nadir PSA. One patient did experience a transient increase in PSA but none reached levels higher than $1.5 \mathrm{ng} / \mathrm{ml}$. Pastuszak et al [51] followed 13 men with predominantly low and intermediate risk prostate cancer treated with testosterone therapy after either brachytherapy or EBRT for $30 \mathrm{mo}$. No biochemical recurrences were noted in this 2013 report.

In the largest radiation therapy series to date, Pastuszak et al [52] describe a multiinstitutional cohort of 98 men given testosterone therapy after being treated with radiation (brachytherapy or EBRT) for prostate cancer. The median follow-up in this 2015 study was $40.8 \mathrm{mo} ; 76.6 \%$ of the cohort had low or intermediate risk prostate cancer. A clinically insignificant increase in mean PSA was noted from $0.08 \mathrm{ng} / \mathrm{ml}$ to $0.09 \mathrm{ng} / \mathrm{ml}(p=0.05)$. Six $(6.1 \%)$ men met either Phoenix or American Society for Radiation Oncology criteria for biochemical recurrence during the study period with two of those requiring subsequent initiation of ADT. Two of these were treated with brachytherapy and may have been experiencing a "PSA bounce" rather than true biochemical recurrence. The authors noted that a $6 \%$ biochemical recurrence rate would indeed be lower than previously reported rates for radiation therapy, although the limited sample size, retrospective study design, and single-arm cohort makes drawing definitive conclusions challenging [52].

Using linked, Surveillance, Epidemiology, and End Results Medicare data, Kaplan et al [53] identified 149354 men diagnosed with prostate cancer between 1992 and 2007. In that cohort, $1181(0.79 \%)$ had used testosterone therapy after being diagnosed with prostate cancer. Using propensity-scoring analysis, the authors found that use of testosterone after diagnosis was not associated with overall mortality, cancer-specific mortality, or the subsequent use of salvage ADT. These results remained consistent when the cohort was classified by cancer stage, grade, and treatment type. In a follow-up study, Kaplan et al [54] used time-varying analysis to show that increasing duration of testosterone therapy usage in this same cohort did not increase mortality or the use of salvage ADT. In both of these large, population-based studies, prostate cancer treatment type (including active surveillance/ watchful waiting) was statistically controlled for and results did not change. Although outcomes of testosterone use in men with untreated prostate cancer was not the primary outcome in either of these studies, the results are provocative.

\subsection{Testosterone therapy in men with untreated prostate cancer}

Reports of testosterone therapy in men on active surveillance or watchful waiting for prostate cancer are more limited. Morgentaler and Rhoden [55] framed this topic in literature as early as 2006 when they found that $15 \%$ of men with TD and a PSA of $4.0 \mathrm{ng} / \mathrm{ml}$ or less had biopsy-detectable prostate cancer. To that end, treating a man with a normal PSA and TD without rule-out biopsy is akin to offering testosterone therapy to men with prostate cancer 15\% of the time. In 2011, Morgentaler et al [56] reported their experience with the treatment of 13 testosterone-deficient men with testosterone therapy that were on an active surveillance protocol for localized prostate cancer. The median follow-up duration was 30 
mo. Twelve men had low risk disease and one had intermediate risk prostate cancer. All men had a follow-up biopsy as a part of their protocol. No upgrading or prostate cancer progression events were reported [56].

In another 2011 study, Morales [57] reported his experience with testosterone therapy in seven patients with untreated prostate cancer. Six men had low risk disease while one had high risk Gleason grade 4+4 disease. Two were given testosterone intermittently. The author recommends proceeding with caution as the PSA responses in this small series were erratic. It must be noted, however, no follow-up biopsies were performed in these patients and only PSA kinetics was studied [57]. Although the use of testosterone therapy in men on active surveillance may appear to push the limits of safety, it is worth noting that low free testosterone concentrations were found to be an independent predictor of disease reclassification (ie, progression) in a study of 154 men on an active-surveillance protocol [58].

Recently, Kacker et al [59] investigated prostate cancer progression rates in testosteronedeficient men on active surveillance. Progression rates in men being treated with testosterone therapy were compared with those not being treated for TD. This retrospective review included 28 men in the treatment arm and 96 men untreated for TD. The authors found that biopsy progression rates were similar between groups over a 3-yr follow-up period [59]. These preliminary data suggest that there may be prognostic value in obtaining serum testosterone tests during active surveillance. Overall, the evidence on testosterone therapy in men with untreated prostate cancer remains sparse, and caution is indicated in this population.

\subsection{Normalizing testosterone levels may be important in prostate cancer control; the concept of bipolar androgen treatment}

Recent data suggest that using testosterone therapy to optimize serum androgen concentrations may play an important role in prostate cancer control. This suggestion is supported by several findings in literature. Low serum testosterone is associated with highergrade prostate cancer [40-42]. Conversely, in young men with peak lifetime testosterone concentrations, prostate cancer is exceedingly rare. Song and Khera [60] exposed prostate cancer cell lines to varying levels of androgen in vitro. Cells exposed to physiologically normal levels of androgen experience inhibited growth patterns. Likewise, in-vivo studies using low androgen adapted LNCaP human prostate cancer xenografts demonstrate inhibited prostate cancer growth under exogenous androgen exposure. Chuu et al [61] showed that nude mice that were derived from androgen adapted (ie, androgen receptor saturated) LNCaP cell lines experienced rapid cancer cell growth in the absence of androgen. When the mice were implanted with a testosterone pellet, reaching supraphysiologic testosterone levels they experienced sustained tumor regression.

These early data suggesting a benefit of androgen normalization in prostate cancer triggered investigation into bipolar androgen therapy (BAT) for the treatment of castrate resistant prostate cancer (CRPC). In CRPC, androgen receptor expression persists despite maximal androgen ablation. Paradoxically, some androgen receptor-expressing "androgen-sensitive" prostate cancer cells can be inhibited by exposure to supraphysiologic androgen levels [62]. 
The possible explanations behind this phenomenon are that high androgen levels inhibit relicensing of DNA in cells expressing high-levels of androgen receptor or that androgens induce breakage in double-strand DNA of rapidly dividing cells [62]. Issacs et al [63] suggest that CRPC cells acquire adaptive autoregulation to increase androgen receptor expression in a low androgen environment. Early pilot data from the same investigators suggest that capitalizing on that androgen receptor up-regulation through acute supraphysiologic androgen followed by acute ablation (ie, BAT) is effective in xenografts [63]. Early pilot clinical data suggest BAT may restore CRPC cells to androgen-sensitivity to traditional ADT [64]. While these data are to date preliminary, they are nonetheless hypothesis generating and thought-provoking in light of the dramatic shift in our understanding of the role androgens play in prostate cancer. Indeed, that testosterone is being used to treat CRPC suggests the conceptual shift regarding androgens and prostate cancer is nearly complete. If testosterone can be used as a treatment in men with prostate cancer, this underscores the notion that testosterone therapy in men with no residual disease is neither radical nor dangerous.

\section{Discussion}

Over the past decade, there has been an important paradigm shift in the understanding of the relationship between androgen levels and prostate cancer. Huggins and Hodges' [9] seminal work identifying the impressive effect of androgen withdrawal (ie, castration) on prostate cancer was of paramount significance. However, misinterpretation of his original work led to erroneous conclusions surrounding testosterone therapy in men with prostate cancer. We now have convincing evidence that: (1) TD is detrimental to health and has a significant impact on quality of life, (2) testosterone therapy can mitigate these untoward effects, (3) high levels of endogenous androgen does not increase the risk or severity of prostate cancer, (4) testosterone therapy does not increase the risk or severity of prostate cancer, and that (5) the impact of androgen on prostatic cells is subject to a saturation effect (Table 2) [10]. The several studies described above, including single-institution case series, multi-institution series, and population-based studies, have not found a higher than expected risk of prostatecancer progression or recurrence in men that received testosterone therapy that were previously treated for prostate cancer. Although small in number, these studies include those treated with radiation-based as well as extirpative therapies.

Despite these data and the marked paradigm shift, the administration of testosterone to men with a history of prostate cancer remains controversial. In a recent German survey-based retrospective study, researchers sent questionnaires to all registered urologists in Bavaria, Germany [65]. Forty-six percent $(n=193)$ responded to the request, which inquired about the urologist's experience with testosterone therapy in men with a history of prostate cancer. Among the 193 urologists, only 32 cases of testosterone therapy in men with prostate cancer were reported [65]. In a 2012 description of international testosterone utilization patterns, Gooren and Behre [11] provide updated follow-up data from a prior 2006 analysis to compare usage in 2010. Prostatic disease remained a significant barrier to testosterone administration in several countries. Accordingly, $11 \%$ of eligible patients did not receive testosterone therapy. In meta-analyses, TD is associated with obesity, metabolic syndrome, and sexual dysfunction. Testosterone therapy is effective in mitigating many sequelae of 
these conditions [66-68]. Through comprehensive systematic review, we show that to date, the evidence overwhelmingly suggests testosterone therapy does not increase the risk of prostate cancer. Mediated by mechanisms explained in the saturation model, testosterone therapy does not appear to cause prostate cancer recurrence in men that have been treated for their malignancy. Early data also suggests that testosterone does not cause prostate cancer progression in the untreated. These findings represent a paradigm shift challenging a urologic maxim that dates back $75 \mathrm{yr}$. Despite the reassuring nature of these findings, continued scrutiny is needed.

In a 2014 review, Khera et al [8] laid out criteria to consider before initiating testosterone therapy in men with a history of prostate cancer: (1) clinicians should confirm that the clinical history is consistent with a laboratory diagnosis of TD, (2) the prescribing clinician must disclose that there are limited data confirming testosterone safety and that the true risks are unknown, (3) he/she must obtain informed consent, (4) confirm that there are no medical contraindications (ie, erythrocytosis), (5) the PSA should be either undetectable or stable, (6) clinicians must be prepared for a prostate cancer recurrence (the authors note that this recurrence may or may not have any relation whatever to the testosterone therapy but might be interpreted as such by the patient), (7) testosterone therapy should be used with extreme caution in men at high risk for prostate cancer recurrence or progression, and (8) it is not recommended that testosterone be concomitantly administered with ADT [8].

We expand upon these criteria in Table 3. This table reflects the authors' expert opinions and recommendations in light of the aforementioned limitations in the data. As understanding of the effects of testosterone therapy on the prostate continues to evolve, these criteria can serve as a guide by which clinicians can approach TD in a thoughtful, effective manner.

\section{Conclusions}

In this systematic review, we show that the use of testosterone therapy does not increase the risk of developing prostate cancer nor worsen its severity if previously diagnosed. Through the framework of the saturation model, we now know that androgens have a finite ability to stimulate prostate cancer cells. This paradigm shift has allowed clinicians to treat TD in men with a history of prostate cancer. Testosterone therapy in men that have a history of prostate cancer does not appear to increase the rate of recurrence or progression. Although a definitive assessment of risk would require long-term controlled data, no study is currently underway to assess testosterone risk in prostate cancer. To that end, clinicians must use their best judgment with the available evidence at hand. With careful clinical monitoring using the criteria listed in Table 3, we believe testosterone therapy can be safely used to treat TD in men with a history of prostatic malignancy. We strongly encourage research efforts in this area, which should include well-designed, adequately powered prospective controlled studies of testosterone therapy in men with prostate cancer.

\section{Acknowledgments}

Funding/Support and role of the sponsor: None. 


\section{References}

1. Surampudi PN, Wang C, Swerdloff R. Hypogonadism in the aging male diagnosis, potentials benefits, and risks of testosterone replacement therapy. Int J Endocrinol. 2012; 2012:625434. [PubMed: 22505891]

2. Harman SM, Metter EJ, Tobin JD, Pearson J, Blackman MR. Baltimore Longitudinal Study of Aging. Longitudinal effects of aging on serum total and free testosterone levels in healthy men. Baltimore longitudinal study of aging. J Clin Endocrinol Metab. 2001; 86:724-31. [PubMed: 11158037]

3. Wu FC, Tajar A, Beynon JM, et al. Identification of late-onset hypogonadism in middle-aged and elderly men. N Engl J Med. 2010; 363:123-35. [PubMed: 20554979]

4. SEER Cancer Statistics Factsheets: Prostate Cancer. National Cancer Institute; Bethesda, MD, USA: http://seer.cancer.gov/statfacts/html/prost.html

5. Wang C, Cunningham G, Dobs A, et al. Long-term testosterone gel (AndroGel) treatment maintains beneficial effects on sexual function and mood, lean and fat mass, and bone density in hypogonadal men. J Clin Endocrinol Metab. 2004; 89:2085-98. [PubMed: 15126525]

6. Traish AM, Miner MM, Morgentaler A, Zitzmann M. Testosterone deficiency. Am J Med. 2011; 124:578-87. [PubMed: 21683825]

7. Morgentaler A. Testosterone and prostate cancer: an historical perspective on a modern myth. Eur Urol. 2006; 50:935-9. [PubMed: 16875775]

8. Khera M, Crawford D, Morales A, Salonia A, Morgentaler A. A new era of testosterone and prostate cancer: From physiology to clinical implications. Eur Urol. 2014; 65:115-23. [PubMed: 24011426]

9. Huggins C, Hodges CV. The effect of castration, of estrogen and of androgen injection on serum phosphatase on metastatic carcinoma of the prostate. Cancer Res. 1941; 1:293-7.

10. Morgentaler A, Traish AM. Shifting the paradigm of testosterone and prostate cancer: the saturation model and the limits of androgen-dependent growth. Eur Urol. 2009; 55:310-21. [PubMed: 18838208]

11. Gooren LJ, Behre HM. Diagnosing and treating testosterone deficiency in different parts of the world: changes between 2006 and 2010. Aging Male. 2012; 15:22-7. [PubMed: 22284307]

12. Kutscher W, Wolbergs H. Prostataphosphatase. Z Physiol Chem. 1935; 236:237-40.

13. White JW. The present position of the surgery of the hypertrophied prostate. Ann Surg. 1893; 18:152.

14. Cabot AT. The question of castration for enlarged prostate. Ann Surg. 1896; 24:265.

15. Morales A, Schulman C, Tostain J, Wu FC. Testosterone deficiency syndrome (TDS) needs to be named appropriately — the importance of accurate terminology. Eur Urol. 2006; 50:407-9. [PubMed: 16854520]

16. Schulman CC, Fusco F, Morales AM, Tostain J, Vendeira P, Zitzmann M. Testosterone deficiency: A common, unrecognized syndrome? Eur Urol Suppl. 2009; 8:772-7.

17. Dohle, GR.; Arver, S.; Bettocchi, S., et al. European Association of Urology web site; Guidelines on male hypogonadism. http://uroweb.org/wp-content/uploads/EAU-Guidelines-MaleHypogonadism-2015.pdf. Updated 2015

18. Isidori AM, Giannetta E, Greco EA, et al. Effects of testosterone on body composition, bone metabolism and serum lipid profile in middle-aged men: a meta-analysis. Clin Endocrinol (Oxf). 2005; 63:280-93. [PubMed: 16117815]

19. Bhasin S, Calof OM, Storer TW, et al. Drug insight: testosterone and selective androgen receptor modulators as anabolic therapies for chronic illness and ageing. Nat Clin Pract Endocrinol Metab. 2006; 2:146-59. [PubMed: 16932274]

20. Lunefeld B, Mskhalaya G, Zitzmann M, et al. Recommendations on the diagnosis, treatment and monitoring of hypogonadism in men. Aging Male. 2015; 18:5-15. [PubMed: 25657080]

21. Corona G, Isidori AM, Buvat J, et al. Testosterone supplementation and sexual function: a metaanalysis study. J Sex Med. 2014; 11:1577-92. [PubMed: 24697970]

22. Zarrouf FA, Artz S, Griffith J, Sirbu C, Kommor M. Testosterone and depression: systematic review and meta-analysis. J Psychiatr Pract. 2009; 15:289-305. [PubMed: 19625884] 
23. Cooper CS, Perry PJ, Sparks AE, MacIndoe JH, Yates WR, Williams RD. Effect of exogenous testosterone on prostate volume, serum and semen prostate specific antigen levels in healthy young men. J Urol. 1998; 159:441-3. [PubMed: 9649259]

24. Bhasin S, Storer TW, Brman N, et al. The effects of supraphysiologic doses of testosterone on muscle size and strength in normal men. N Engl J Med. 1996; 335:1-7. [PubMed: 8637535]

25. Monath JR, McCullough DL, Hart LJ, Jarow JP. Physiologic variations of serum testosterone within the normal range do not affect serum prostate-specific antigen. Urology. 1995; 46:58-61. [PubMed: 7541587]

26. Traish AM, Williams DF, Hoffman ND, Wotan HH. Validation of the exchange assay for the measurement of androgen receptors in human and dog prostates. Prog Clin Biol Res. 1988; 262:145-60. [PubMed: 3375279]

27. Traish AM, Muller RE, Wotiz HH. A new procedure for the quantitation of nuclear and cytoplasmic androgen receptors. J Biol Chem. 1981; 256:12028-33. [PubMed: 6975277]

28. Marks LS, Mazer NA, Mostaghel E, et al. Effect of testosterone replacement therapy on prostate tissue in men with late-onset hypogonadism: a randomized controlled trial. JAMA. 2006; 296:2351-61. [PubMed: 17105798]

29. Khera M, Bhattacharya RK, Blick G, Kushner H, Nguyen D, Miner MM. Changes in prostate specific antigen in hypogonadal men after 12 months of testosterone replacement therapy: support for the prostate saturation theory. J Urol. 2011; 186:1005-11. [PubMed: 21788049]

30. Morgentaler A, Benesh JA, Denes BS, Kan-Dobrosky N, Harb D, Miller MG. Factors influencing prostate-specific antigen response among men treated with testosterone therapy for 6 months. $\mathrm{J}$ Sex Med. 2014; 11:2818-25. [PubMed: 25131184]

31. Rastrelli G, Corona G, Vignozzi, et al. Serum PSA as a predictor of testosterone deficiency. J Sex Med. 2013; 10:2518-28. [PubMed: 23859334]

32. Roddam AW, Allen NE, Appleby P, Key TJ. Endogenous sex hormones and prostate cancer: a collaborative analysis of 18 prospective studies. J Natl Cancer Inst. 2008; 100:170-83. [PubMed: 18230794]

33. Muller RL, Gerber L, Moreira DM, Andriole G, Castro-Santamaria R, Freedland SJ. Serum testosterone and dihydrotestosterone and prostate cancer risk in the placebo arm of the reduction by dutasteride of prostate cancer events trial. Eur Urol. 2012; 62:757-64. [PubMed: 22658758]

34. Calof OM, Singh AB, Lee ML, et al. Adverse events associated with testosterone replacement in middle-aged and older men: a meta-analysis of randomized, placebo-controlled trials. J Gerontol A Biol Sci Med Sci. 2005; 60:1451-7. [PubMed: 16339333]

35. Feneley MR, Carruthers M. Is testosterone treatment good for the prostate? Study of safety during long-term treatment. J Sex Med. 2012; 9:2138-49. [PubMed: 22672563]

36. Shabsigh R, Crawford ED, Nehra A, Slawin KM. Testosterone therapy in hypogonadal men and potential prostate cancer risk: a systematic review. Int J Impot Res. 2009; 21:9-23. [PubMed: 18633357]

37. Haider A, Zitzmann M, Doros G, Isbarn H, Hammerer P, Yassin A. Incidence of prostate cancer in hypogonadal men receiving testosterone therapy: observations from 5-year median follow up of 3 registries. J Urol. 2015; 193:80-6. [PubMed: 24980615]

38. Kaplan AL, Hu JC. Use of testosterone replacement therapy in the United States and its effect on subsequent prostate cancer outcomes. Urology. 2013; 82:321-6. [PubMed: 23706552]

39. Baillargeon J, Kuo YF, Fang X, Shahinian VB. Long-term exposure testosterone therapy and the risk of high grade prostate cancer. J Urol. 2015; 194:1612-6. [PubMed: 26066403]

40. Rhoden EL, Morgentaler A. Testosterone replacement therapy in hypogonadal men at high risk for prostate cancer: results of 1 year of treatment in men with prostatic intraepithelial neoplasia. $\mathrm{J}$ Urol. 2003; 170:2348-51. [PubMed: 14634413]

41. Røder MA, Christensen IJ, Berg KD, Gruschy L, Brasso K, Iversen P. Serum testosterone level as a predictor of biochemical failure after radical prostatectomy for localized prostate cancer. BJU Int. 2012; 109:520-4. [PubMed: 21851535]

42. Salonia A, Abdollah F, Capitanio U, et al. Serum sex steroids depict a nonlinear u-shaped association with high-risk prostate cancer at radical prostatectomy. Clin Cancer Res. 2012; 18:3648-57. [PubMed: 22589393] 
43. Léon P, Seisen T, Cussenot O, et al. Low circulating free and bioavailable testosterone levels as predictors of high-grade tumors in patients undergoing radical prostatectomy for localized prostate cancer. Urol Oncol. 2015; 33:384.e21-7. [PubMed: 25595576]

44. Kaufman JM, Graydon RJ. Androgen replacement after curative radical prostatectomy for prostate cancer in hypogonadal men. J Urol. 2004; 172:920-2. [PubMed: 15310998]

45. Agarwal PK, Oefelein MG. Testerone replacement therapy after primary treatment for prostate cancer. J Urol. 2005; 173:533-6. [PubMed: 15643240]

46. Khera M, Grober ED, Najari B, et al. Testosterone replacement therapy following radical prostatectomy. J Sex Med. 2009; 6:1165-70. [PubMed: 19207277]

47. Pastuszak AW, Pearlman AM, Lai WS, et al. Testosterone replacement therapy in patients with prostate cancer after radical prostatectomy. J Urol. 2013; 190:639-44. [PubMed: 23395803]

48. Sarosdy MF. Testosterone replacement for hypogonadism after treatment of early prostate cancer with brachytherapy. Cancer. 2007; 109:536-41. [PubMed: 17183557]

49. Balbontin FG, Moreno SA, Bley E, Chacon R, Silva A, Morgentaler A. Long-acting testosterone injections for treatment of testosterone deficiency after brachytherapy for prostate cancer. BJU Int. 2014; 114:125-30. [PubMed: 25101359]

50. Morales A, Black AM, Emerson LE. Testosterone administration to men with testosterone deficiency syndrome after external beam radiotherapy for localized prostate cancer: preliminary observations. BJU Int. 2009; 103:62-4. [PubMed: 18671790]

51. Pastuszak AW, Pearlman AM, Godoy G, Miles BJ, Lipschultz LI, Khera M. Testosterone replacement therapy in the setting of prostate cancer treated with radiation. Int J Impot Res. 2013; 25:24-8. [PubMed: 22971614]

52. Pastuszak AW, Khanna A, Badhiwala N, et al. Testosterone therapy after radiation therapy for low, intermediate, and high risk prostate cancer. J Urol. 2015; 194:1271-6. [PubMed: 26025500]

53. Kaplan AL, Trinh QD, Sun M, et al. Testosterone replacement therapy following the diagnosis of prostate cancer: outcomes and utilization trends. J Sex Med. 2014; 11:1063-70. [PubMed: 24443943]

54. Kaplan AL, Lenis AT, Shah A, Rajfer J, Hu JC. Testosterone replacement therapy in men with prostate cancer: a time-varying analysis. J Sex Med. 2015; 12:374-80. [PubMed: 25496237]

55. Morgentaler A, Rhoden EL. Prevalence of prostate cancer among hypogonadal men with prostatespecific antigen levels of $4.0 \mathrm{ng} / \mathrm{ml}$ or less. Urology. 2006; 68:1263-7. [PubMed: 17169647]

56. Morgentaler A, Lipshultz LI, Bennett R, Sweeney M, Avila D Jr, Khera M. Testosterone therapy in men with untreated prostate cancer. J Urol. 2011; 185:1256-60. [PubMed: 21334649]

57. Morales A. Effect of testosterone administration to men with prostate cancer is unpredictable: a word of caution and suggestions for a registry. BJU Int. 2011; 107:1369-73. [PubMed: 21518230]

58. San Francisco IF, Rojas PA, DeWolf WC, Morgentaler A. Low free testosterone levels predict disease reclassification in men with prostate cancer undergoing active surveillance. BJU Int. 2014; 114:229-35. [PubMed: 24898919]

59. Kacker, R.; Mariam, H.; San Francisco, IF., et al. Can testosterone therapy be offered to men on active surveillance for prostate cancer? Preliminary results. Asian J Androl. In press http:// dx.doi.org/10.4103/1008-682X.160270

60. Song W, Khera M. Physiological normal levels of androgen inhibit proliferation of prostate cancer cells in vitro. Asian J Androl. 2014; 16:864-8. [PubMed: 24923459]

61. Chuu CP, Hiipakka RA, Fukuchi, Kokontis JM, Liao S. Androgen causes growth suppression and reversion of androgen-independent prostate cancer xenografts to an androgen-stimulated phenotype in athymic mice. Cancer Res. 2005; 65:2082-4. [PubMed: 15781616]

62. Denmeade SR, Issacs JT. Bipolar androgen therapy: the rationale for rapid cycling of supraphysiologic androgen/ablation in men with castrate resistant prostate cancer. Prostate. 2010; 70:1600-7. [PubMed: 20607766]

63. Issacs JT, D'Antonio JM, Chen S, et al. Adaptive auto-regulation of androgen receptor provides a paradigm shifting rationale for bipolar androgen therapy (BAT) for castrate resistant human prostate cancer. Prostate. 2012; 72:1491-505. [PubMed: 22396319] 
64. Schweizer MT, Antonarakis ES, Wang S, et al. Effect of bipolar androgen therapy for asymptomatic men with castrate-resistant prostate cancer: results from a pilot clinical study. Sci Transl Med. 2015; 7:269ra2.

65. Kühn CM, Strasser H, Romming A, et al. Testosterone replacement therapy in hypogonadal men following prostate cancer treatment: A questionnaire-based retrospective study among urologists in Bavaria, Germany. Urol Int. 2015; 95:153-9. [PubMed: 25677365]

66. Corona, G.; Vignozzi, L.; Sforza, A.; Mannucci, E.; Maggi, M. Obesity and late-onset hypogonadism. Moll Cell Endocrinol. In press http://dx.doi.org/10.1016/j.mce.2015.06.031

67. Brand JS, Rovers MM, Yeap BB, et al. Testosterone, sex hormone binding globulin and the metabolic syndrome in men: an individual participant data meta-analysis of observational studies. PLoS One. 2014; 9:e100409. [PubMed: 25019163]

68. Isidori AM, Buvat J, Corona G, et al. A critical analysis of the role of testeosterone in erectile function: from pathophysiology to treatment-a systematic review. Eur Urol. 2014; 65:99-112. [PubMed: 24050791] 
We review and summarize existing literature surrounding testosterone therapy in men with prostate cancer. Historically, testosterone was contraindicated in men with prostate cancer. We show that this contraindication is unfounded and testosterone use is safe with careful monitoring. 


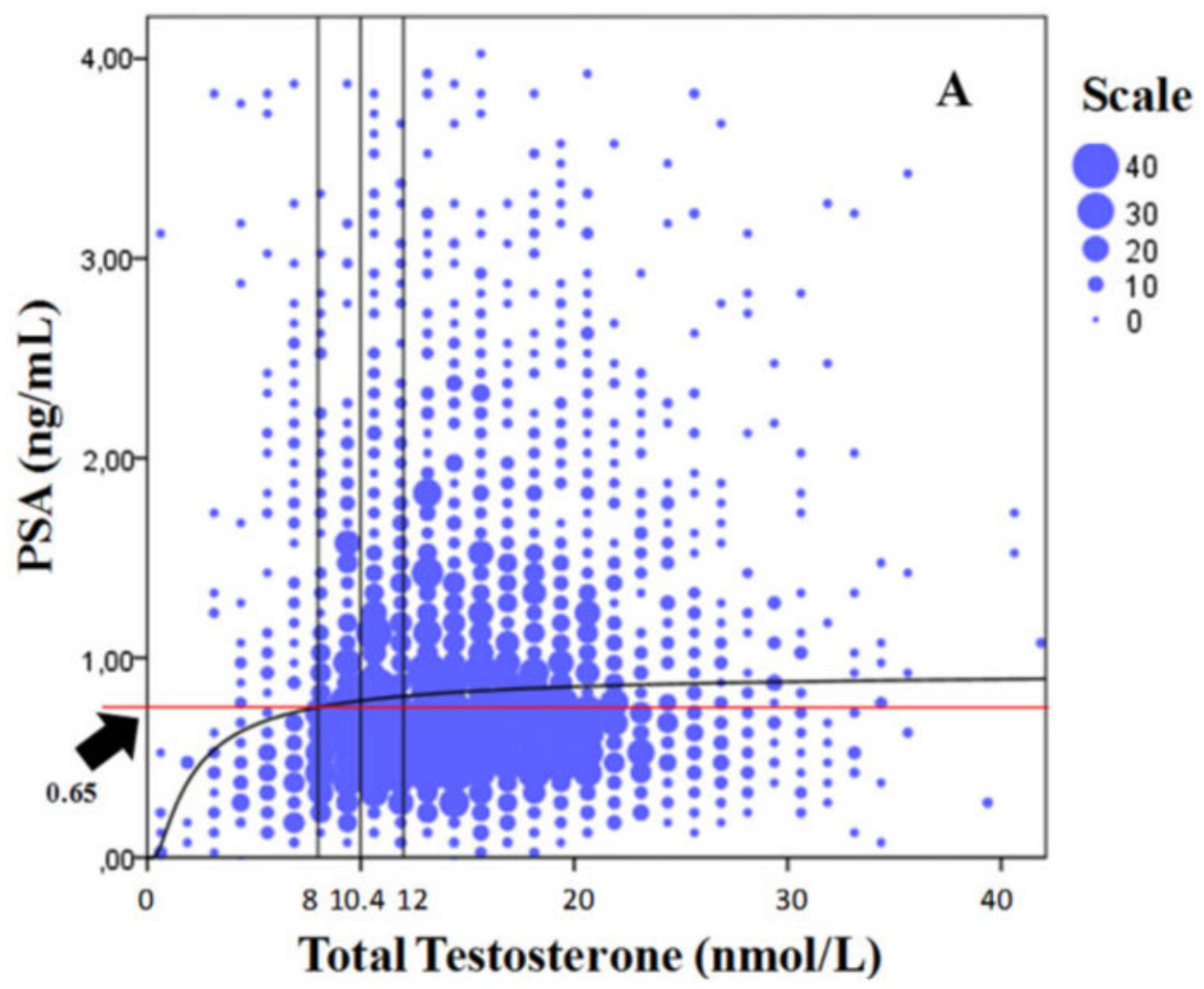

Fig.1. Prostate-specific antigen versus total testosterone. PSA = prostate-specific antigen 
Table 1

Summary of known evidence regarding testosterone deficiency

\begin{tabular}{|l|l|}
\hline Known evidence in testosterone deficiency & Levels of evidence \\
\hline TD confers negative impact on health and quality of life [17-22] & $1 \mathrm{a}$ \\
\hline Testosterone therapy can mitigate untoward effects of TD [17-22] & $1 \mathrm{a}$ \\
\hline $\begin{array}{l}\text { Higher endogenous serum androgen concentrations are not associated with increased risk of developing prostate cancer, } \\
\text { or severity of prostate cancer [32,33] }\end{array}$ & $1 \mathrm{a}$ \\
\hline Testosterone therapy is not associated with increased risk or severity of prostate cancer [34-40] & $2 \mathrm{a}$ \\
\hline Impact of androgen on prostate cells is subject to a saturation effect [7,9,10,26-28] & $2 \mathrm{~b}$ \\
\hline
\end{tabular}

$\mathrm{TD}=$ testosterone deficiency. 


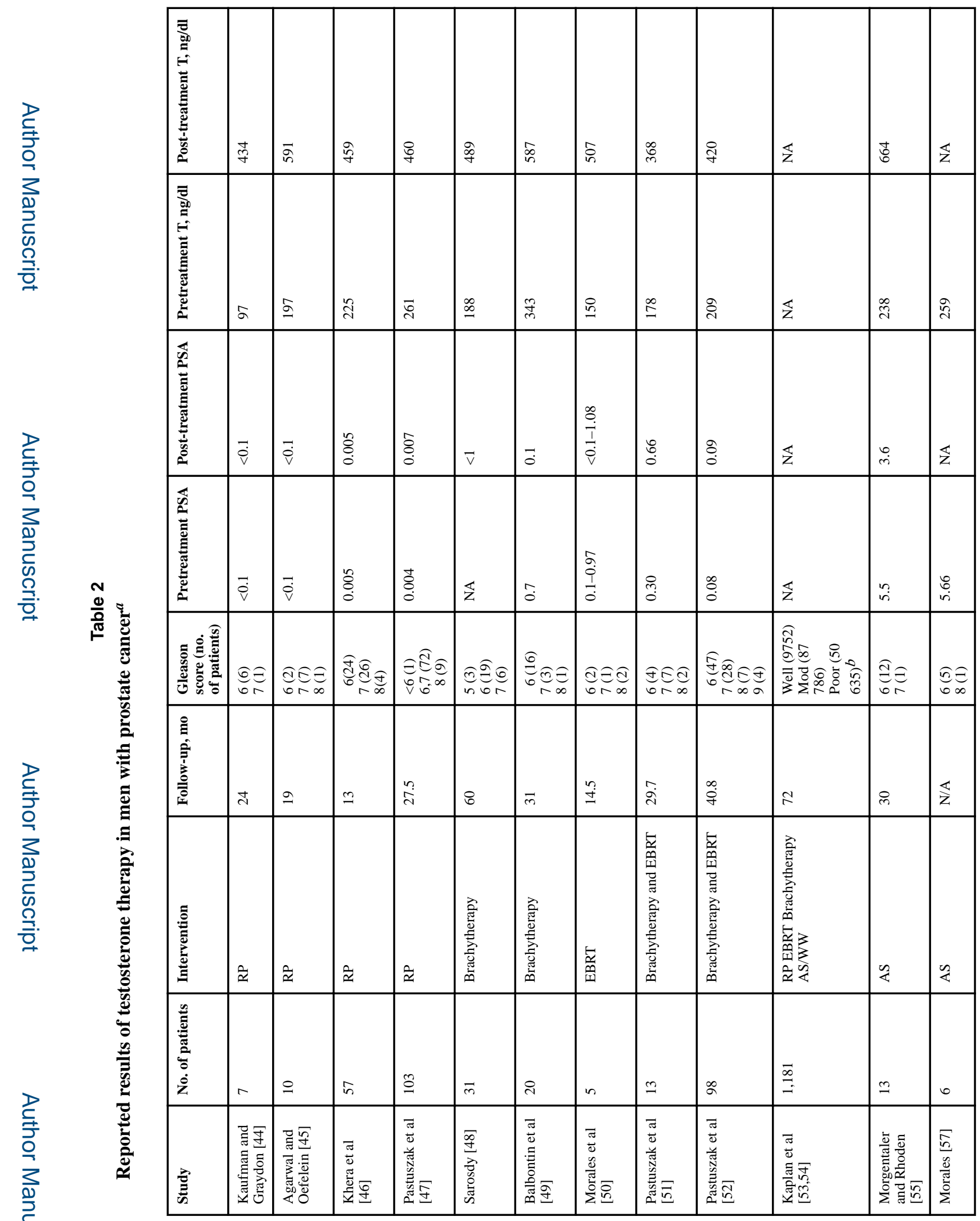

Eur Urol. Author manuscript; available in PMC 2017 May 01. 


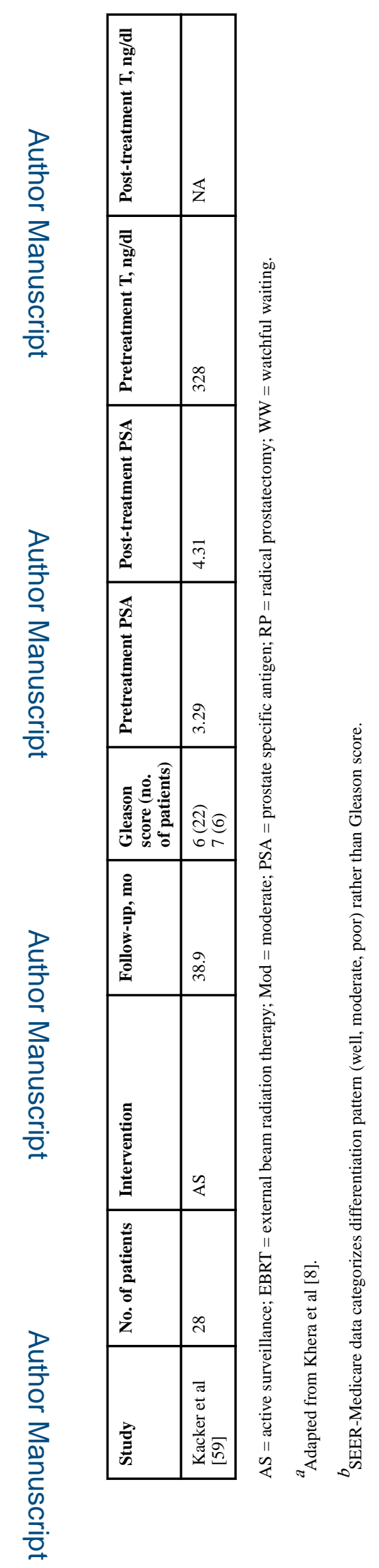

Eur Urol. Author manuscript; available in PMC 2017 May 01. 
Table 3

Authors' recommendations in managing testosterone deficiency in men with history of prostate cancer $^{a}$

\begin{tabular}{|c|c|c|}
\hline Recommendation & Level of evidence & Grade \\
\hline \multicolumn{3}{|l|}{ Prior to initiating testosterone therapy } \\
\hline The clinical history should be consistent with a laboratory diagnosis of testosterone deficiency. & - & S \\
\hline The clinician must disclose that data are limited confirming safety and that true risk is unknown. & - & S \\
\hline The clinician should use shared decision-making and obtain informed consent. & - & S \\
\hline Confirm there are no medical contraindications (eg, erythrocytosis) to testosterone therapy. & - & S \\
\hline $\begin{array}{l}\text { PSA should be either undetectable following radical prostatectomy or stable following radiation treatment } \\
\text { over a 6-mo period. Exercise extreme caution in men at high risk for recurrence or progression. }\end{array}$ & - & S \\
\hline Testosterone therapy should not be given with ADT unless in a clinical trial. & - & S \\
\hline \multicolumn{3}{|l|}{ Suitable options for testosterone therapy } \\
\hline $\begin{array}{l}\text { Short-acting formulations are preferred for initial treatment. Longer-acting treatments such as intramuscular } \\
\text { testosterone undecanoate or subcutaneous pellets may be considered once it becomes clear that testosterone } \\
\text { therapy has not caused progression or recurrence. }\end{array}$ & 3 & B \\
\hline \multicolumn{3}{|l|}{ Following initiation of testosterone therapy } \\
\hline $\begin{array}{l}\text { Clinicians must be prepared for prostate cancer recurrence. This may or may not be related to testosterone } \\
\text { therapy but may be interpreted as such by the patient, his family, or other clinicians. }\end{array}$ & - & $\mathrm{S}$ \\
\hline Measure hematocrit and/or hemoglobin $2-4$ times in the $1^{\mathrm{st}} \mathrm{yr}$, then annually. & 4 & $\mathrm{C}$ \\
\hline $\begin{array}{l}\text { Measure PSA every } 3-4 \text { mo in the } 1^{\text {st }} \mathrm{yr} \text { after initiating testosterone and twice a yr thereafter. Perform DRE } 1- \\
2 \text { times within } 1^{\text {st }} \mathrm{yr} \text {, then annually. }\end{array}$ & 4 & $\mathrm{C}$ \\
\hline $\begin{array}{l}\text { Men on AS should undergo annual prostate biopsy to ensure cancer stability. Longer intervals may be } \\
\text { considered after disease stability has been determined, as per local AS protocols. }\end{array}$ & - & $\mathrm{S}$ \\
\hline
\end{tabular}

$\mathrm{A}=$ based on clinical studies of good quality and consistency addressing the specific recommendations and including at least one randomized trial; $\mathrm{ADT}=$ androgen deprivation therapy; $\mathrm{AS}=$ active surveillance; $\mathrm{B}=$ based on well-conducted clinical studies, but without randomized clinical trials; $\mathrm{C}=$ made despite the absence of directly applicable clinical studies of good quality; DRE = digital rectal exam; PSA = prostate-specific antigen; $\mathrm{S}=$ strong recommendation by expert opinion in absence of direct clinical evidence; $1 \mathrm{a}=$ evidence obtained from meta-analysis of randomized trials; $1 \mathrm{~b}=$ evidence obtained from at least one randomized trial; $2 \mathrm{a}=$ evidence obtained from systematic review of cohort studies; $2 \mathrm{~b}=$ evidence obtained from individual cohort studies; 3 = evidence obtained from case-control studies; 4 = evidence obtained from expert committee reports.

${ }^{a}$ Modification of criteria outlined by Khera et al [8]. Adapted from 2015 European Association of Urology guidelines on male hypogonadism [17] and recommendations by the International Society for the Study of the Aging Male [20]. 